\title{
PETUALANGAN ASTRONOT DALAM KARYA SENI ILUSTRASI DIGITAL
}

\author{
Zul Fiqhri \\ Universitas Negeri Makassar \\ e-mail : zulfiqhri18@gmail.com \\ Diterima: 12 Agustus 2018. Disetujui : 9 November 2018. Dipublikasikan : 1 Desember 2018 \\ (O2018 - DESKOVI Universitas Maarif Hasyim Latif. Ini adalah artikel dengan akses terbuka di \\ bawah lisensi CC BY 4.0 (https://creativecommons.org/licenses/by/4.0/)
}

\begin{abstract}
ABSTRAK
Tulisan ini membahas mengenai bagaimana petualangan astronot dalam proses penjelajahan dalam kehidupan sehari-hari. Astronout dipilih karena pelukis menganggap bahwa astronot adalah petualang yang mencoba untuk mebuka tabir kehidupan lain yang ada di jagat raya, astronot adalah manusia yang berani untuk maju menyelami pengetahuan akan dunia luar yang belum di jamah oleh manusia pada umumnya. Tulisan ini akan membahas tentang karya ilustrasi astronot dalam petualangan untuk mengupas arti di balik kehidupan sehari-hari.
\end{abstract}

Kata kunci: astronot, petualangan

\section{ABSTRACT}

This article discusses how the astronauts adventures in the process of exploration in everyday life. Astronauts are chosen because painters consider astronauts to be adventurers who try to open another veil of life in the universe, astronauts are human beings who dare to advance to explore a knowledge from outside world that has not been recognized by humans in general. This paper will discuss the work of astronaut illustrations in adventures to explore the meaning behind everyday life.

Keywords: astronauts, adventure

\section{PENDAHULUAN}

Ekspedisi atau petualangan luar angkasa seringkali memberikan berbagai macam pertanyaan yang tak lazim didalamnya. Ketika maknanya yakni penjelajahan angkasa dalam melintasi ruang dan waktu, menjumpai berbagai persoalan-persoalan yang terkadang pelik, ditambah itu terkadang tak ditemukan hanya di permukaan di bumi. Yah, seperti itulah perjalanan langit. Perjalanan yang misterius, penuh akan tanya yang tak bertepian, selalu menemukan fenomena tak lazim yang terkadang mengagetkan suasana pada ulu hati. Yaitu perjalanan mengenal dunia diluar kehidupan kita.

Kita terkadang menganggap sesuatu yang terjadi berjalan begitu saja. Sama seperti siklus yang hanya dibiarkan untuk berputar agar permasalahanpermasalan terlewati begitu saja. Tapi, pernahkan kita berfikir bahwa setiap perjalanan kehidupan adalah sebagai bentuk pebelajaran yang tersirat? ebuah petualangan yang mesti dimengerti makna dalam pengaplikasiannya sehingga dari pembelajaran akan makna tersebut, kita bisa makin mendewasa dalam bertindak dan mengambil keputusan. Bagaimana jika dalam menjalani kehidupan ini, kita menganggap diri kita ini adalah astronot yang menjelajahi setiap makna kehidupan, pasti kita mendapat keberanian untuk bisa menafsirkan hasil apa yang dapat di peroleh dari penjelajahan yang telah kita lewati hari ini. Perjalan yang seperti ini seakan tak pernah berhenti menyikap semua persoalan-persoalan baru, mencoba menafsirkan berbagai fenomena sehingga menghasilkan intuisi baru, menghasilkan ruang gerak baru sesuai dengan penafsirnya, sehingga ruang-ruang itupun berkembang menjadi sebuah persepsi baru dan dijadikan sebagai dasar wacana. Yah, ruang Imajinasi. Pada dasarnya, ruang yang kita kenal ini, merupakan ruang dimana sebuah perjalanan yang antah berantah terjadi, kita tak pernah tahu bagaimana akhirnya, sehingga berbagai persepsi-pun terkadang dapat di satukan meski dalam realitanya tak pernah terhubung satu dengan yang lainnya. Mungkin karena perbedaan dimensi, yakni dimensi ruang dan waktu.

Konsep bentuk yang mendukung untuk menjelaskan tentang bagaimana wacana perjalanan ini adalah bentuk perjalanan angkasawan, seorang astronot. Mengapa Astronot?, sebab dari pandangan personal penulis yang melihat sebuah petualangan spiritual, petualangan jenis seperti ini sama halnya dengan penjelalajan yang sifatnya untuk mencoba “ 
melampaui" realitas itu sendiri. Mencoba melakukan perjalanan menebus dimensi ruang dan waktu, mengintari garis horizon hingga dapat mengunjungi berbagai kebudayaan di waktu yang berbeda, serta mencoba melakukan perjalanan yang sifatnya diluar nalar bagi sebagian orang.

Ketika kita membandingkan bagaimana sensasi manusia yang ingin menjelajahi "lebih dari apa yang didunia ini" maka manusia itu menjadi Astronot untuk menjelajahi luar angkasa. Jika memang seperti itu, maka petualangan sehari-hari pun demikian, sebab bagaimana kita bisa melakukan petualangan yang sifatnya hanya duniawi ketika visi masa depan kita adalah "Melampaui keduniawian itu sendiri" sehingga apa yang terkadang dipikirkan dalam petualangan kita, dapat kita hubungkan dengan segala sesuatunya. Petualangan yang bukan hanya menyangkut petualangan di permukaan bumi, tetapi petualangan dalam menembus relasi langit dan bumi.

Tujuan dari penelitian ini adalah meningkatkan kepekaan hidup bahwa dari pengalaman hidup sehari-hari kita dapat dijadikan sebagai objek seni yang sifatnya inspiratif agar menjadi sebuah proses dengan hasil yang kreatif. Berdasarkan dari perjalanan yang menjadi inspirasi dalam pembuatan karya seni dimasa kini.

\section{METODE PENCIPTAAN}

Teori yang digunakan yaitu pendekatan seni yang ditulis oleh M Dwi Marianto, dalam bukunya Art and Life Force menegaskan Bahwa seni sebagai kata benda abstrak 'seni' adalah kemampuan kreatif manusia dalam menanggapi alam; kemampuan menangani suatu yang menuntut pemecahan masalah; sebuah kemampuan istimewa dalam mengubah suatu ide menjadi suatu yang menarik, fungsional, atau inspiratif (Marianto, 2017, p. 3)

Metode penciptaan yang digunakan yaitu metode observasi. Observasi dalam buku metodologi penciptaan seni adalah semacam peninjauan secara cermat, sedangkan mengobservasi adalah mengawasi dengan teliti, mengamati" (Sari, 2010, p. 3). Dari kutipan inilah kita bisa mengetahui pendekatan apa yang pas untuk bisa membahasakan bagaimana tema dalam petualangan astronot yang dimetaforkan dalam persepsi personal dan diangkat pada problema kehidupan sehari-hari.

Adapun langkah-langkah yang digunakan ialah mengamati subjek secara mendalam dan melihat kepekaan tentang fakta objektif yang di dapatkan sehingga bisa menjadi bagian dari kepekaan rasa untuk dijadikan sebagai momen estetis. Melibatkan metafora-metafora dalam komunikasi untuk bisa juga mendapatkan kepekaan yang lebih tajam dalam hal memaknai suatu karya.

Metode ini diperkuat dengan menambahkan unsur-unsur karikatur di dalam menyampaikan gagasan pada karya. Dalam buku Art \& Life Force mengutip pendapat sukasman bahwa prose penyangatan, hiperbola, atau pengkarikaturan diperlukan dalam membuat karakter-karakter wayang, sesungguhnya dapat diterapkan untuk cabang seni apa saja”. (Marianto, 2017, p. 11).

Berdasarkan kutipan diatas, kita bisa mengetahui bagaimana pengkarikaturan dalam karya bisa dijadikan sebagi landasan untuk membuat pekaryaan menjadi semakin menarik, menjadi semakin berbicara lebih dari apa yang terlihat.

\section{PEMBAHASAN}

Dari beberapa sampel kisah yang dijadikan karya seni untuk menceritakan kehidupan sehari-hari sebagai petualang dalam perilaku kreatif, karya menampilkan berbagai macam dinamika rasa yang menjadi bumbu dalam pengolahan ide dan penyampaian rasa.

\section{Astromie}

Kisah dalam karya ini terinspirasi dari bagaimana persoalan mensyukuri nikmat dalam kehidupan. Terkadang dalam hidup ini, kita selalu bimbang dalam mencari arti kebahagiaan. Sebenarnya, kebahagiaan yang bagaimana yang sebenarnya kita cari? Kita selalu merasa bahwa kebahagiaan adalah hal yang mewah yang terkadang kita mesti harus mewujudkannya di masa depan nanti. Tetapi, apakah kita tahu bahwa kebahagiaan itu bisa kita ciptakan sendiri? kebahagiaan yang kita ciptakan berasal dari rasa kesyukuran kita dalam merasa cukup akan sesuatu. Karya ini menjelaskan tentang bagaimana kebahagiaan didapatkan dalam semangkuk hangat mie yang dicampur dengan berbagai penambah lauk untuk melengkapkan rasanya. Semangkuk ini mengisahkan tentang bagaimana kita bisa dengaan rendah hati ingin menikmati kebahagiaan dalam kesederhanaan semangkuk panas mie, sambil menikmatinya di atas meja yang berselimut dan menonton acara televisi favorit kita. Sungguh,siapa sangka dengan modal yang sangat sedikit, tak perlu mencari kemewahan, ataupun menjelajahi tempat-tempat yang menawan ternyata kebahagiaan bisa kita dapatkan dalam hal yang sesederhana ini, jika hati kita ingin membuka kesyukuran, maka sesuatu yang sangat berarti akan dapat tercipta dari hal yang biasa tersebut.

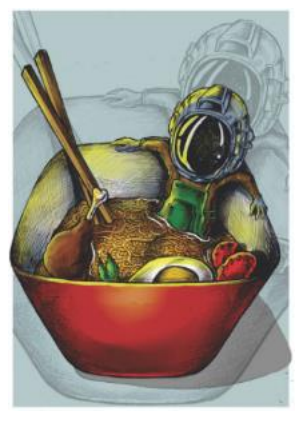

Gambar 1.Astromie Sumber: Karya Pribadi 


\section{Hot \& cold}

Di dalam karya ini, saya menuliskan tentang keluh kesah diriku akan pertanyaan-pertanyaan yang mengganggu dari dalam hati. Apakah ini tentang persahabatan, tentang cinta, tentang masa depan, atau tentang kepercayaan. Terkadang merasa bahwa pertanyaan-pertanyaan tersebut seolah mengganggu saya dalam melangkahkan kaki kedepan. Saya merasa seperti mengalami krisis daya hidup. Sampai aku pun bertanya pada beberapa objek disudut ruangan yang terpaku, dan hanya diam menyaksikan kebimbanganku. Aku seolah melakuakn percakapa spiritual dengan lingkungan sekitarku.

Aku kembali menatap sekitarku dan melihat dispenser. Mengapa dispenser? Aku melihat bahwa ada sensasi antara panas dan dingin yang ia tawarkan. Aku melihat dualitas, melihat sebuah pilihan yang memberikanku inspirasi bahwa, "jika aku tidak dapat melalui sebuah jalan, mengapa saya memaksakan diri untuk bimbang dengan terus melangkah di jalan itu?, mengapa engkau tidak meilih jalan lain selama itu masih bisa kau berjuang didalamnya?" aku merasa bahwa aku harus percaya Allah. "Allah selalu mempunyai rencana terbaik untuk setiap kita. Ia menempatkan jodoh terbaik, untuk melihat siapa finalis terbaik. Finalis yang bertahan di putaran arus kehidupan" (Ramdani, 2017, p. 92)

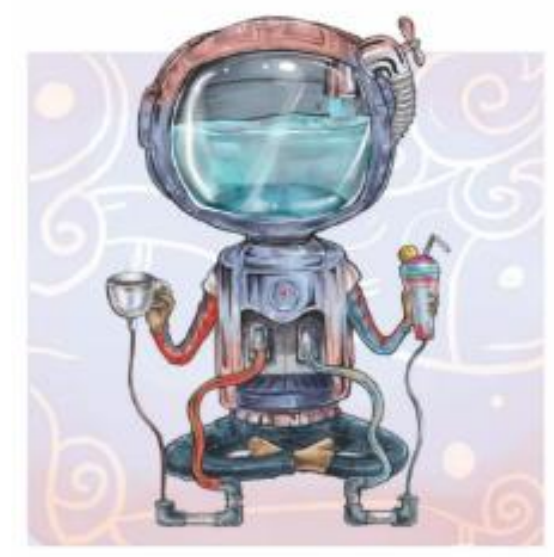

Gambar: 2.Hot and cool

Sumber: Karya Pribadi

\section{Gender}

Aku percaya, bahwa didalam tubuh kita ada dua sisi yag berbeda, yaitu maskulin dan feminim. Aku merasa terkadang mencintai petualangan yang menengangkan serta bisa saja aku menyukai keindahan yang lembut, menyegarkan mata, dan mengademkan rasa, seperti yang disukai oleh gadisgadis pada umumnya.

Apakah didalam tubuh ini yang mempunyai dua hasrat yang saling berlwanan?, aku terkadang seolah memikirkan itu. Karya ini, yang berjudul "Gender" membuatku merasa bahwa saya harus menuliskan sesuatu yang terdapat didalam diri saya, sisi maskulin dan feminis yang kerapkali muncul pada kondisikondisi tertentu.

Saya menggambarkan pose dalam karya ini seperti simbol Gemini yang biasa digunakan oleh para peramal zodiac. Simbol dari Gemini itu merepresentasikan bentuk dari gender laki-laki dan perempuan yang bisa dikatakan kembar. Di dalam buku Mamang muhamad haeruddin yang berjudul Tuhan Izinkan Aku Mencintai Perempuan, dia mengutip perkataan ibnu 'Arabi yaitu "Perempuan adalah saudara kandung laki- laki di alam roh dan tubuh kasar, keduanya satu dalam eksistensi, itulah manusia, perbedaan antara mereka aksiden semata. Perempuan dan laki-laki memang beda." (Haerudin, 2013, p. 19)

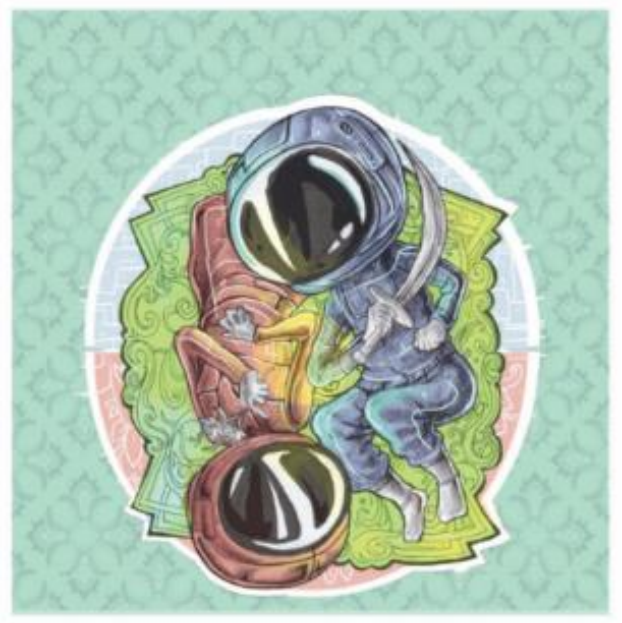

Gambar 3. Gender

Sumber: Karya Pribadi

\section{Siklus}

Siklus dalam sebuah kehidupan seperti halnya siklus air yang kita pakai. Ketika kita ingin mengambil air pada sumber air, kita mesti menggunakan mesin pompa untuk menyerap air itu, setelah itu air dialirkan ke bak-bak mandi kita. Setelah kita memakai air pada bak mandi tersebut, air yang jatuh tadi akan masuk kedalam lubang pembuangan, sehingga terserap kembali oleh tanah dan bersatu lagi dengan sumber air yang pertama yaitu diserap dari dalam tanah.

Proses ini mengingatkan saya pada kehidupan masa lalu, ketika saya melakukan sesuatu yang baik, atau buruk, ada saja saatnya ketika saya akan menerima balasan yang setimpal tersebut kedalam diri saya lagi. Ketika saya menyakiti seseorang, maka suatu saat saya akan disakiti juga dengan seseorang, begitupun sebaliknya.

Proses siklus yang terjadi ini biasa dinamakan dengan siklus kehidupan, ketika ada momen didalam hidup yang berputar seolah roda, kadang kita Berjaya dan kadang kita sengsara. Kadang kita di puncak teratas, kadang juga kita di kasta terbawah. 


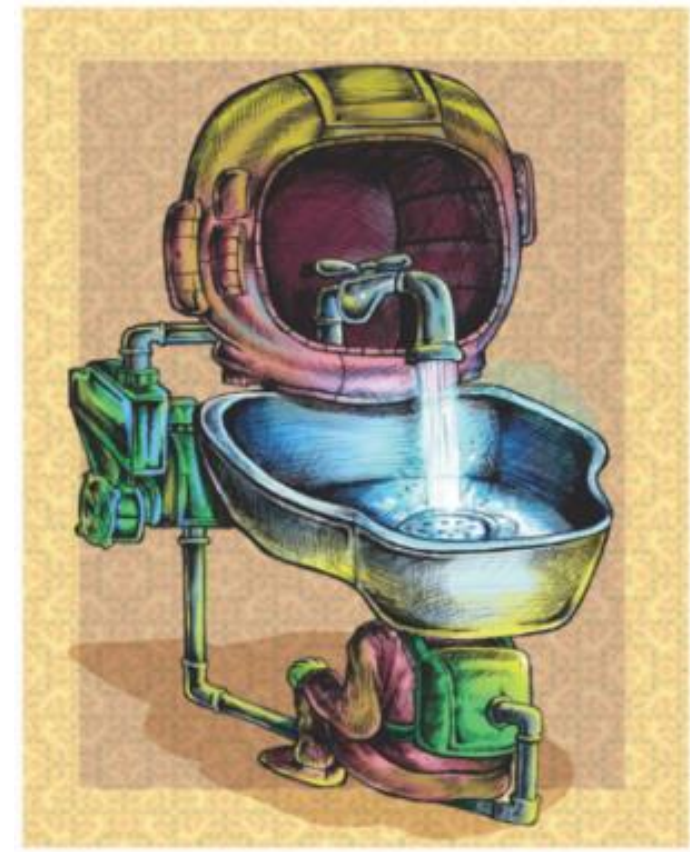

Gambar 4.Siklus

Sumber: Karya Pribadi

\section{Astrowizard}

Di dalam hidup apakah kau percaya sihir?, itu yang terkadang saya tanyakan didalam diri. Apakah mungkin segala sesuatu terjadi begitu saja?, sihir yang mungkin seringkali rang sebutkan mungkin akan membawa kita ke imaji tentang sesuatu yang menyeramkan, sesuatu yang digunakan oleh seseorang yang mempunyai kekuatan agis dan membcakan mantra didepan ramuan-ramuan kimia sebagai ramuan sihirnya. Tapi di kehidupanku, sihir tak seperti itu. Sihir bagiku adalah ketika aku mempercayai akan sesuatu dan membuat daya akan jiwaku membara dan menjadi spirit untuk menumbuhkan keberanian. Sama halnya ketika saya menyukai seseorang dan mungkin saya tidak berani untuk menyatakan perasaan, malah menatap wajahnya saja rasanya kurang mungkin. Jawabannya ada pada diri kita asing-masing.

Terkadang saya menyiapkan mantra tertentu ketika hendak melakukan sesuatu agar lebih berani dari biasanya. Yah "terkadang memang butuh sihir untuk mencairkan hati yang telah lama beku, tapi sebenarnya apakah memang hati ini yang beku? ataukah ucap ini belum tangguh setangguh aku sebenarnya menginginkanmu?." Kalimat inilah yang terkadang aku ucapkan didalam hati ketika mempertanyakan keberanian itu pada diri sendiri.

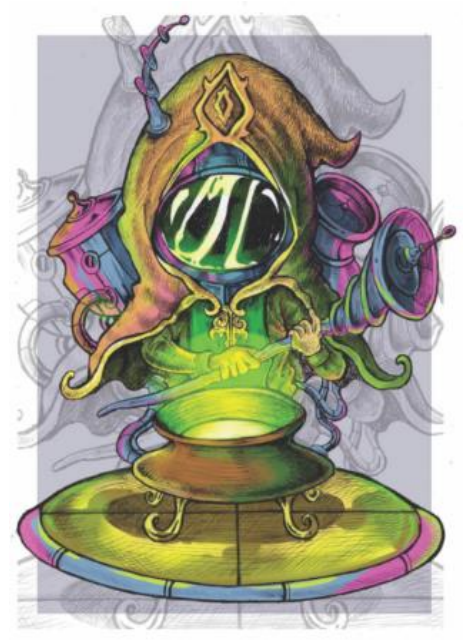

\section{Gambar 5.Astrowizard Sumber: Karya Pribadi}

\section{KESIMPULAN}

Dalam berkarya seni kita mesti dituntut untuk berfikir dan bertindak seperti layaknya astronot. Sosok yang berani mengambil resiko demi mengisi dahaga akan sebuah pengetahuan dunia diluar sana yang masih menjadi misteri. Penyelaman seperti astronot, membuat kita menjadi lebih peka akan melihat sesuatu. Melihat sebuah kondisi keseharian yang membangkitkan rasa penasaran untuk lebih menggali lagi makna apa yang ada di balik keseharian tersebut. Dari beberapa karya yang telah di jelaskan, kita menjadi yakin bahwa disekitar kita sangat banyak kumpulan ruh ide yang dapat dijadikan sebagai sumber dalam berkesenian. Kita tinggal hanya memilih bahwa apakah kita ingin melihat dunia dengan kepekaan seperti cara pandang astronot atau kita melihat dunia dengan cara pandang biasa saja, itu tergantung kita masing-masing.

\section{DAFTAR PUSTAKA}

Haerudin, M. M. (2013). Tuhan, Mohon Izinkan Aku Mencintai Perempuan. Jakarta: Penerbit PT Elex Media Komputindo.

Marianto, M. D. (2017). Art \& Life Force. Yogyakarta: Scritto Books Publisher.

Oxford Learner's Pocket Dictionary. (2008). Oxford. Ramdani, F. (2017). Tuma'ninah. Surakarta: Bebuku Publisher.

Sari, N. L. D. I. D. (2010). Metodologi Penciptaan Seni. Yogyakarta: Institute Seni Indonesia Yogyakarta. 